\title{
Zespół rozdęcia torebki soczewki - rzadkie powikłanie po operacji zaćmy
}

\section{Capsular bag distension syndrome: an uncommon complication following cataract surgery}

Piotr Kanclerz, Katarzyna Przewłócka

Przychodnia Lekarska Hygeia w Gdańsku Kierownik: dr n. med. Piotr Kanclerz

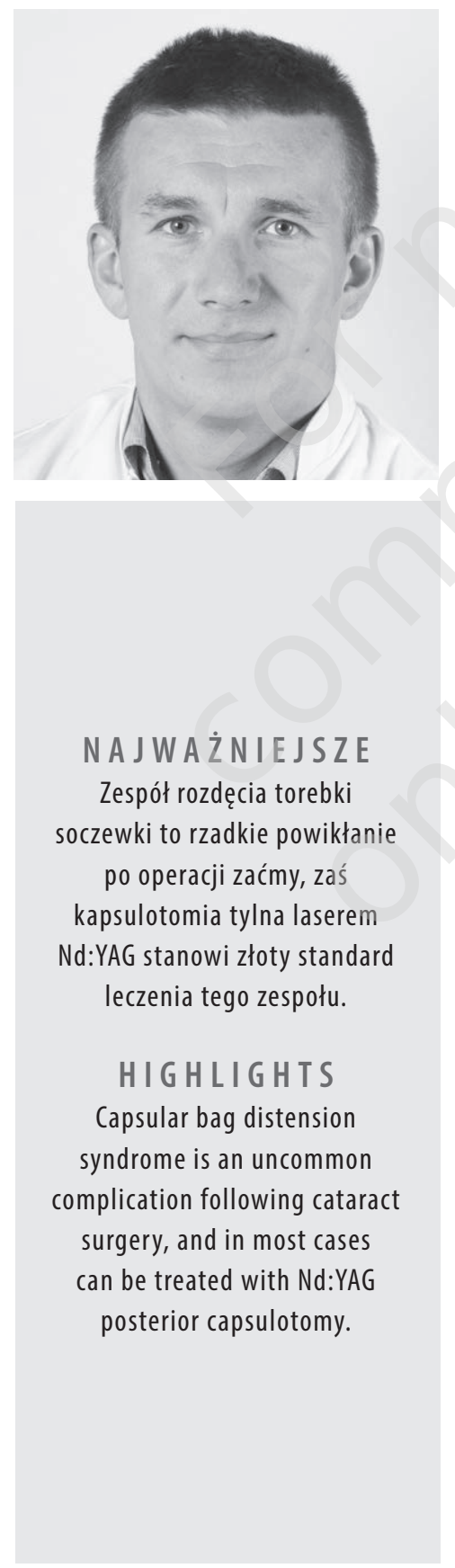

\section{STRESZCZENIE}

Zespół rozdęcia torebki soczewki jest rzadkim powikłaniem po operacji usunięcia zaćmy, które może się rozwinąć nawet wiele lat po zabiegu. Do głównych objawów zalicza się nagłe lub stopniowe przesunięcie wady refrakcji w kierunku krótkowzroczności, a w przypadku zmętnienia płynu wewnątrztorebkowego również pogorszenie ostrości wzroku. Optyczna koherentna tomografia przedniego odcinka oka może potwierdzić rozpoznanie, pomocne może być także obrazowanie kamerą Scheimpfluga bądź biomikroskopią ultradźwiękową. Za złoty standard leczenia uznaje się kapsulotomię tylną (ewentualnie przednią) laserem Nd:YAG. Korzyścią z leczenia chirurgicznego jest możliwość całkowitego usunięcia płynu wewnątrztorebkowego. W poniższej pracy przedstawiono współczesną klasyfikację, metody diagnostyczne i zasady postępowania w zespole rozdęcia torebki soczewki.

Słowa kluczowe: zespół rozdęcia torebki soczewki, powikłania pooperacyjne, operacja zaćmy, fakoemulsyfikacja

\section{ABSTRACT}

Capsular bag distension syndrome is an uncommon complication following cataract extraction, which may occur even several years after surgery. The main symptoms include a gradual or sudden development of myopia and - in cases with opaque intracapsular fluid - a decrease in visual acuity. Anterior segment-optical coherence tomography is useful in confirming the diagnosis, however, Scheimpflug imaging or ultrasound biomicroscopy can also be considered. Nd:YAG posterior (or anterior) capsulotomy is an established treatment method. An advantage of surgical treatment is the feasibility of removing the intracapsular fluid completely. This article presents the modern classification, diagnostic methods and principles of management in the capsular bag distension syndrome.

Key words: capsular bag distension syndrome, postoperative complication, cataract surgery, phacoemulsification 


\section{WSTĘP}

Pooperacyjny zespół rozdęcia torebki soczewki (CBDS, capsular bag distension syndrome) to rzadko występujące powikłanie po operacji zaćmy, które jest opisywane u 0,73-1\% pacjentów [1]. Może się ono rozwinąć kilka dni po operacji, natomiast jego objawy - w ciągu kilku lat [1]. Zespół ten charakteryzuje się ścisłym przyleganiem sztucznej soczewki wewnątrzgałkowej (IOL, intraocular lens) do brzegów kapsuloreksji, co skutkuje gromadzeniem się płynu wewnątrz torebki soczewki. W konsekwencji dochodzi do rozdęcia torebki tylnej oraz przesunięcia IOL ku przodowi. Gromadzący się między soczewką a torebką płyn może mieć mętną konsystencję, co prowadzi do pogorszenia ostrości wzroku [2].

\section{KLASYFIKACJA CBDS}

Dotychczas zaproponowane zostały trzy klasyfikacje CBDS. Pierwsza z nich opiera się na czasie wystąpienia objawów po operacji zaćmy [3]. Wyróżnia się śródoperacyjny, wczesny pooperacyjny i późny pooperacyjny CBDS. Śródoperacyjny CBDS związany jest z gwałtownym wzrostem objętości płynu wewnątrz torebki soczewki w obszarze jej tylnego bieguna podczas wykonywania hydrodysekcji lub dalszych faz zabiegu. Może on wystąpić, jeżeli odpływ płynów z przestrzeni pomiędzy torebką tylną a IOL jest utrudniony, oraz prowadzić do pęknięcia torebki tylnej i zwichnięcia jądra soczewki. Do czynników ryzyka wystąpienia śródoperacyjnego CBDS zalicza się zaćmę biegunową tylną, zaćmę dojrzałą, wysoką długość osiową gałki ocznej, a także zbyt szybką podaż dużej objętości płynu [4]. Śródoperacyjny CBDS opisywany jest również w operacji zaćmy laserem femtosekundowym. Wczesny pooperacyjny CBDS rozwija się w ciągu 2 tygodni od operacji i jest spowodowany nadmiernym wzrostem objętości płynu za IOL. Typowe objawy tego stanu to nieoczekiwana pooperacyjna krótkowzroczność, wzrost ciśnienia wewnątrzgałkowego oraz spłycenie komory przedniej [5]. Charakterystycznym obrazem klinicznym dla późnego pooperacyjnego CBDS jest pogorszenie ostrości wzroku, a zmiany refrakcji związane z patologicznym przesunięciem soczewki wewnątrzgałkowej, w przeciwieństwie do wczesnego pooperacyjnego CBDS, nie są tak nasilone [6].

Inny podział pooperacyjnego CBDS opiera się na występowaniu charakterystycznych cech klinicznych - wyróżnia się postać acelularną, zapalną oraz włókniejącą [7]. W typie acelularnym CBDS dochodzi do rozdęcia torebki soczewki, a także przesunięcia IOL ku przodowi w ciągu kilku dni po przeprowadzonej operacji usunięcia zaćmy. Przyczyną tego stanu jest najczęściej niepełne wypłukanie wiskoelastyku podczas operacji zaćmy [7]. Postać zapalna CBDS również rozwija się w ciągu kilku dni po operacji i wiąże się z nasiloną reakcją w komorze przedniej, a nawet obecnością włóknika. Postać włókniejąca CBDS występuje w późnym okresie pooperacyjnym i może się rozwinąć nawet do
20 lat po zabiegu zaćmy. Charakterystyczne jest występowanie zwłóknienia na całym obwodzie torebki soczewki, zaś za główną przyczynę powstałych zmian uważa się proliferację komórek nabłonka soczewki oraz ich pseudometaplazję.

Trzecia klasyfikacja, zaproponowana przez Vlasenko i wsp., proponuje podział CBDS pod względem obecności lub braku zmętnienia torebki tylnej soczewki oraz wyróżnia postać z przeźroczystym lub zmętniałym płynem wewnątrztorebkowym [8].

\section{OBJAWY KLINICZNE}

Główne objawy CBDS we wczesnym okresie pooperacyjnym obejmują nagłe wystąpienie krótkowzroczności oraz mierną poprawę ostrości wzroku po operacji zaćmy. Krótkowzroczność wywołana zespołem rozdęcia torebki soczewki związana jest z przednim przesunięciem IOL, a stopień nasilenia krótkowzroczności - z objętością płynu zgromadzonego w torebce. Opisywane są przypadki CBDS z krótkowzrocznością sięgającą -4,5 D [9]. Nadwzroczność wywołana CBDS występuje rzadziej, ale opisano ją u $20 \%$ chorych z CBDS i nasilonym włóknieniem torebki soczewki [10]. Wystąpienie nadwzroczności ma najprawdopodobniej związek ze zwiększonym współczynnikiem refrakcji światła przechodzącego przez płyn wewnątrztorebkowy, czego następstwem jest spadek mocy tylnej powierzchni soczewki [10].

Rozdęcie tylnej torebki soczewki w przebiegu CBDS, zwłaszcza we wczesnym okresie pooperacyjnym, może spowodować przesunięcie tęczówki ku przodowi oraz spłycenie przedniej komory. W takich sytuacjach rozszerzenie źrenicy może być utrudnione, co dodatkowo skutkuje brakiem możliwości dokładnej oceny torebki soczewki [11]. Mniej powszechnym objawem może być wzrost ciśnienia wewnątrzgałkowego, spowodowany spłyceniem przedniej komory i zwężeniem kąta przesączenia [12].

Utrata ostrości widzenia w późnym okresie pooperacyjnym przebiega zazwyczaj stopniowo i jest następstwem powolnego mętnienia tylnej torebki soczewki oraz płynu znajdującego się w torebce soczewki. W przypadku, gdy dojdzie do rozprzestrzeniania się mętnego płynu w kierunku osi widzenia, może nastąpić nagły spadek ostrości wzroku [13]. Istnieją także doniesienia o bezobjawowym rozwoju CBDS.

Wartościowymi badaniami dodatkowymi umożliwiącymi dokładniejszą ocenę morfologii komory przedniej oraz płynu umieszczonego między tylną torebką soczewki a IOL mogą być zdjęcia wykonane z użyciem kamery Scheimpfluga, biomikroskopia ultradźwiękowa oraz optyczna koherentna tomografia (OCT, optical coherence tomography) [14]. Badanie OCT umożliwia bardziej precyzyjną ocenę morfologii soczewki niż obrazowanie metodą Scheimpfluga, ponieważ większa długość fali świetlnej zastosowana w OCT 
prowadzi do większej przenikalności przez mętny płyn soczewkowy (ryc. 1). W przypadku występowania CBDS na peryferyjnych obszarach soczewki, u pacjentów z wąską źrenicą, korzystna może być metoda biomikroskopii ultradźwiękowej [15].

Czynniki ryzyka pooperacyjnego CBDS zostały zebrane $\mathrm{w}$ tabeli 1 . Wystąpienie tego zespołu we wczesnym okresie pooperacyjnym związane jest z niepełnym oczyszczeniem wiskoelastyku z torebki soczewki [17]. Pozostawiony w torebce materiał wiskoelastyczny powoduje wytworzenie ciśnienia osmotycznego (może dochodzić do dyfuzji płynów przez torebkę soczewki, ale jest ona nieprzepuszczalna dla dużych białek), a w konsekwencji gromadzenie płynu $\mathrm{w}$ torebce soczewki oraz wzrost jej objętości [18]. Śródoperacyjny objaw potwierdzający pełne oczyszczenie to- rebki z wiskoelastyku stanowi pojawienie się fałdów na tylnej powierzchni torebki. Innym czynnikiem sprzyjającym wystąpieniu CBDS jest niedostateczne oczyszczenie torebki z komórek nabłonka soczewki lub nadmierna reakcja zapalna po operacji usunięcia zaćmy [7, 18]. Zwiększenie przepuszczalności bariery krew-siatkówka może sprzyjać różnicowaniu i pseudometaplazji komórek nabłonka soczewki, zaś zwiększony gradient osmotyczny przez torebkę soczewki może doprowadzić do trwałego przylegania IOL do brzegu kapsuloreksji [19]. CBDS obserwuje się również częściej u pacjentów z cukrzycą niż bez niej właśnie z powodu upośledzenia funkcji bariery krew-siatkówka w cukrzycy. Przyczyną późnego pooperacyjnego CBDS może być też zwłóknienie torebki soczewki, zwłaszcza gdy występuje ono w zakresie 360 stopni.

\section{RYCINA 1}
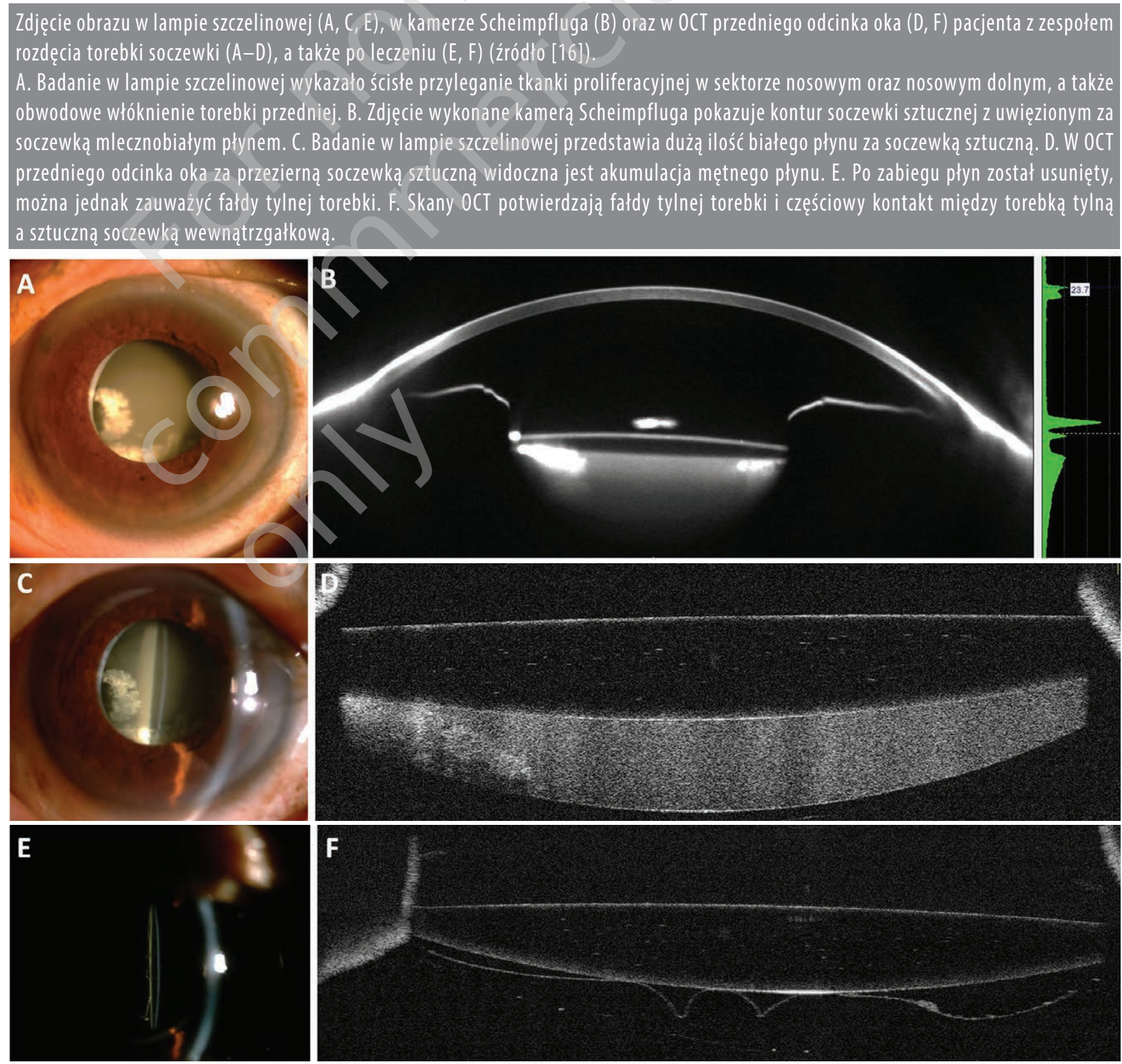


\section{TABELA}

\section{Czynniki ryzyka rozwoju CBDS}

- pozostawienie wiskoelastyku w torebce po operacji zaćmy

- niedostateczne oczyszczenie kory soczewki (zwłaszcza w rzucie cięcia rogówki)

- pooperacyjna reakcja zapalna w obrębie komory przedniej

- mała kapsuloreksja lub nieprawidłowa konfiguracja soczewki wewnątrzgałkowej (brak angulacji, odwrotna implantacja)

- nadkażenie Propionibacterium acnes podczas zabiegu

- głęboka przednia komora

Do rozwoju CBDS może przyczyniać się także nadkażenie Propionibacterium acnes [20]. P. acnes jest beztlenową bakterią Gram-dodatnią, która wytwarza liczne białka powodujące stan zapalny m.in. proteinazy, lipazy oraz hialuronidaze [21]. Charakterystycznym objawem CBDS związanego z obecnością $P$. acnes jest występowanie ogniskowego zmętnienia wewnątrz torebki soczewki. P. acnes może też inicjować rozwój miejscowej reakcji zapalnej w obszarze torebki soczewki, a jego obecność potwierdzono w aspiratach pacjentów z CBDS [20].

Innym czynnikiem ryzyka może być głęboka komora przednia, co utrudnia pełne usunięcie wiskoelastyku oraz możliwość dokładnego oczyszczenia torebki soczewki podczas jej polerowania $[10,18]$.

\section{LECZENIE}

W niektórych przypadkach, zwłaszcza jeżeli nie pojawiają się obniżenie ostrości widzenia lub jakiekolwiek dolegliwości subiektywne, zaleca się jedynie obserwację. Opisywane są przypadki samoistnego ustąpienia objawów CBDS [3]. Jeżeli występuje podejrzenie, że rozwój objawów jest związany ze stanem zapalnym w komorze przedniej, rekomenduje się leczenie miejscowe kroplami steroidowymi [3, 7]. Za złoty standard leczenia CBDS uznaje się kapsulotomię tylną laserem Nd:YAG [22]. Kapsulotomia może prowadzić do przesunięcia refrakcji w kierunku nadwzroczno- ści, nadciśnienia wewnątrzgałkowego, a nawet zapalenia przedniego odcinka błony naczyniowej [23]. Wykonanie kapsulotomii tylnej może być utrudnione lub niemożliwe w przypadku obrzęku rogówki, zbyt słabego rozszerzenia źrenicy, a także nadmiernego zmętnienia płynu wewnątrz torebki soczewki. W takich sytuacjach alternatywę może stanowić wykonanie kapsulotomii przedniej. Kapsulotomia przednia może być korzystna zwłaszcza w przypadku obecności małej kapsuloreksji o cechach włóknienia. Problemem w przypadku kapsulotomii przedniej jest nasilona ekspozycja komory przedniej na zmętniały płyn wewnątrztorebkowy, co z kolei może doprowadzić do odczynu zapalnego i większego niż przypadku kapsulotomii tylnej podwyższenia ciśnienia wewnątrzgałkowego. Co więcej, po kapsulotomii przedniej lub tylnej opisywano pofałdowanie torebki tylnej soczewki, które powodowało obniżenie jakości widzenia.

Inną opcją leczenia CBDS jest interwencja chirurgiczna polegająca na wykonaniu kapsulektomii mechanicznej oraz usunięciu wewnątrztorebkowego płynu z dostępu przez pars plana. Stosuje się przy tym instrumentarium takie samo jak w przypadku bezszwowej witrektomii małego cięcia. Metoda jest stosunkowo prosta technicznie, a dostęp do torebki soczewki - łatwy. Korzyść wynikająca z zastosowania tej metody stanowi możliwość całkowitego usunięcia wewnątrztorebkowego płynu, co ma istotne znaczenie zwłaszcza w przypadkach podejrzanych o nadkażenie P. acnes [20, 23].

\section{PODSUMOWANIE}

CBDS jest rzadkim powikłaniem po operacji usunięcia zaćmy, które może się rozwinąć nawet wiele lat po zabiegu. Najczęściej dochodzi do przesunięcia wady refrakcji w kierunku krótkowzroczności, a w przypadku zmętnienia płynu wewnątrztorebkowego również pogorszenia ostrości wzroku. Za złoty standard leczenia uznaje się kapsulotomię tylną (ewentualnie przednią) laserem Nd:YAG, zaś korzyścią interwencji chirurgicznej jest możliwość całkowitego usunięcia płynu wewnątrztorebkowego.

\author{
ADRES DO KORESPONDENCJI \\ dr n. med. Piotr Kanclerz \\ 80-286 Gdańsk, ul. Jaśkowa Dolina 57 \\ e-mail: p.kanclerz@gumed.edu.pl \\ tel.: (+48 66) 161-04-61 \\ faks: (+48 58) 776-40-46
}

ORCID:

Piotr Kanclerz - ID - https://orcid.org/0000-0002-8036-7691 


\section{Piśmiennictwo}

1. Kanclerz P, Wang X. Postoperative Capsular Bag Distension Syndrome - Risk Factors and Treatment. Semin Ophthalmol. 2019; 34(6): 409-19.

2. Huerva V, Sánchez MC, Ascaso FJ. Late postoperative capsular block syndrome: a case series studied before and after Nd:YAG laser posterior capsulotomy. Eur J Ophthalmol. 2015; 25: 27-32.

3. Miyake K, Ota I, Miyake S et al. Liquefied aftercataract: a complication of continuous curvilinear capsulorhexis and intraocular lens implantation in the lens capsule. Am J Ophthalmol. 1998; 125: 429-35.

4. Roberts TV, Sutton G, Lawless MA et al. Capsular block syndrome associated with femtosecond laser-assisted cataract surgery. J Cataract Refr Surg. 2011; 37: 2068-70. https://doi.org/10.1016/j.jcrs.2011.09.003.

5. Zacharias J. Early postoperative capsular block syndrome related to saccadic-eye-movement-induced fluid flow into the capsular bag. J Cataract Refract Surg. 2000; 26: 415-9.

6. Neri A, Pieri M, Olcelli F et al. Swept-source anterior segment optical coherence tomography in late-onset capsular block syndrome: high-resolution imaging and morphometric modifications after posterior capsulotomy. J Cataract Refract Surg. 2013; 39: 1722-8.

7. Kim HK, Shin JP. Capsular block syndrome after cataract surgery: clinical analysis and classification. J Cataract Refract Surg. 2008; 34: 357-63.

8. Vlasenko A, Malyugin B, Verzin A et al. Capsular bag distention syndrome: case series and management strategies. Lisbon 2017.

9. Sorenson AL, Holladay JT, Kim T, et al. Ultrasonographic measurement of induced myopia associated with capsular bag distention syndrome. Ophthalmology. 2000; 107: 902-8. https://doi.org/10.1016/s0161-6420(00)00020-8.

10. Yang MK, Wee WR, Kwon JW et al. Anterior chamber depth and refractive change in late postoperative capsular bag distension syndrome: a retrospective analysis. PLoS One. 2015; 10: e0125895.

11. Holtz SJ, Jerome Holtz S. Postoperative capsular bag distension. J Cataract Refract Surg. 1992; 18: 310-7. https://doi.org/10.1016/ s0886-3350(13)80910-8.

12. Jain AK, Sukhija J, Saini JS. Surgical management of early postoperative capsular bag distension syndrome. J Cataract Refract Surg. 2004; 30: 1143-5.

13. Ghanem VC, Ghanem EA. Sudden decrease in vision caused by liquefied after-cataract. J Cataract Refract Surg. 2003; 29:210-2.

14. Zhu XJ, Zhang KK, Yang J et al. Scheimpflug imaging of ultra-late postoperative capsular block syndrome. Eye. 2014; 28: 900-4.

15. Kucukevcilioglu M, Hurmeric V, Erdurman FC et al. Imaging late capsular block syndrome: Ultrasound biomicroscopy versus Scheimpflug camera. J Cataract Refract Surg. 2011; 37: 2071-4. https://doi.org/10.1016/j.jcrs.2011.08.023.

16. Wang X, Dong J, Zhang S, Sun B. OCT Application Before and After Cataract Surgery. In: Lanza M (ed). OCT Application in Ophthalmology. IntechOpen Limited, London 2018; 175-89.

17. Tak H.: Hydroimplantation: Foldable intraocular lens implantation without an ophthalmic viscosurgical device. J Cataract Refract Surg. 2010; 36: 377-9. https://doi.org/10.1016/j.jcrs.2009.10.042.

18. Miyake K, Ota I, Ichihashi S et al. New classification of capsular block syndrome. J Cataract Refract Surg. 1998; 24: $1230-4$.

19. Kitagawa K, Hayasaka S, Nagaki Y. Increased aqueous flare intensity in eyes with liquefied after-cataract. J Cataract Refract Surg. 2004; 30: $1342-4$.

20. Dhaliwal DK. Late capsular block syndrome associated with Propionibacterium acnes. Arch Ophthalmol. 2011; 129: 246. https://doi. org/10.1001/archophthalmol.2010.356.

21. Perry A, Lambert P. Propionibacterium acnes: infection beyond the skin. Expert Rev Anti Infect Ther. 2011; 9: 1149-56.

22. Hawlina G, Drnovšek-Olup B, Možina J et al. Photodisruption of a thin membrane near a solid boundary: an in vitro study of laser capsulotomy. Applied Physics A. 2016; 122. https://doi.org/10.1007/s00339-016-9648-z.

23. Titiyal JS, Falera R, Kaur M et al. Management of late-onset flocculent after-cataract with capsular bag lavage and posterior continuous curvilinear capsulorhexis. Indian J Ophthalmol. 2018; 66: 984-7.

Wkład autorów:

Wszyscy autorzy w równym stopniu przyczynili się do powstania artykułu.

Konflikt interesów:

Nie występuje.

Finansowanie:

Nie występuje.

Etyka:

Treści przedstawione w artykule są zgodne z zasadami Deklaracji Helsińskiej,

dyrektywami EU oraz ujednoliconymi wymaganiami dla czasopism biomedycznych.

\author{
Authors' contributions: \\ All authors contributed equally to the article. \\ Conflict of interest: \\ None. \\ Financial support: \\ None. \\ Ethics:
}

The content presented in the article complies with the principles of the Helsinki Declaration, EU directives and harmonized requirements for biomedical journals. 